\title{
Chronic obstructive pulmonary disease and cognitive impairment in the Chinese elderly population: a large national survey
}

This article was published in the following Dove Press journal:

International Journal of COPD

25 February 2016

Number of times this article has been viewed

\author{
Peng Yin ${ }^{1, *}$ \\ Qingfeng $\mathrm{Ma}^{2, *}$ \\ Limin Wang ${ }^{\prime}$ \\ Peng $\operatorname{Lin}^{3}$ \\ Mei Zhang' \\ Shige Qi' \\ Zhihui Wang'
}

'National Center for Chronic and Noncommunicable Disease Control and Prevention, Chinese Center for Disease Control and Prevention, ${ }^{2}$ Department of Neurology, Xuanwu Hospital of Capital Medical University, Beijing, ${ }^{3}$ Department of Health Education, Qingdao Municipal Center for Disease Control and Prevention, Qingdao, People's Republic of China

*These authors contributed equally to this work
Correspondence: Zhihui Wang

National Center for Chronic and

Noncommunicable Disease Control and

Prevention, Chinese Center for Disease

Control and Prevention, 27 Nanwei

Road, Xicheng District, 100050 Beijing,

People's Republic of China

Tel +86 I0 630I 5058

$\mathrm{Fax}+861063032350$

Email wangzhihui@live.com
Background: Previous studies suggested an association between chronic obstructive pulmonary disease (COPD) and cognitive impairment, mostly in developed countries. There is no evidence available on the association between these two common chronic disorders in the elderly people in People's Republic of China where the population is aging rapidly.

Methods: The study population was randomly selected from a nationally representative Disease Surveillance Point System in People's Republic of China. A standardized questionnaire was administered by trained interviewers during a face-to-face interview in the field survey conducted in 2010-2011. Cognitive function was assessed using the Mini-Mental State Examination. COPD was measured by self-report and the Medical Research Council respiratory questionnaire was used to assess respiratory symptoms. A multivariate logistic regression model was applied to examine the association between COPD and cognitive impairment with adjustment for potential confounding factors.

Results: A total of 16,629 subjects aged over 60 years were included in the study. The prevalence of cognitive impairment was 9.4\% (95\% confidence interval [CI] 7.7, 11.1). Chronic phlegm was associated with significantly higher prevalence of cognitive impairment in models adjusted for age, sex, marital status, geographic region, urban/rural, education, smoking status, alcohol drinking, and indoor air pollution (odds ratio [OR] 1.46, 95\% CI 1.11, 1.93). Chronic respiratory symptoms and self-reported COPD were strongly related to cognitive impairment in urban areas. There were no significant effect modifications for sex, regions, educational level, smoking status, and alcohol drinking.

Conclusion: There was strong association between COPD and cognitive impairment in urban Chinese elderly population.

Keywords: COPD, cognitive impairment, respiratory symptoms

\section{Introduction}

Chronic obstructive pulmonary disease (COPD) is a common chronic disease in elderly people characterized by persistent airflow limitation. ${ }^{1}$ Cognitive impairment, represented as an early manifestation of dementia, is also common in the elderly and will cause huge burden in the family and society worldwide when it progresses to dementia. ${ }^{2}$ Evidence from a well conducted cross-sectional study indicated that mild cognitive impairment was found in $36 \%$ COPD patients compared with $12 \%$ among the control group. ${ }^{3}$ Previous longitudinal cohort studies also showed that reduced lung function was associated with worse performance in cognitive assessments, baseline $\mathrm{FEV}_{1}$ could predict cognitive function and a diagnosis of COPD in midlife was independently associated with cognitive impairment in later life. ${ }^{4-6}$ However, there were 
other studies reporting no difference of cognitive function between community-based COPD patients and healthy controls. ${ }^{7,8}$

The majority of studies examining the relationship between COPD and cognitive impairment were conducted in developed countries. In People's Republic of China, the total number of elderly aged $65+$ is estimated to increase dramatically from 111 million in 2010 to $337-400$ million in $2050,{ }^{9}$ representing the largest number of elderly people in any country in the world. However, there is no evidence available on the association between these two common chronic diseases in the elderly Chinese population. Whether there is an association between chronic respiratory disease and cognitive impairment remain unknown for this aging country. This is important to study because preventing chronic respiratory diseases with early interventions, such as health education campaigns to stop smoking or reduce exposure to indoor air pollution from biomass combustions, may reduce late-life cognitive impairment.

The aims of the present study were to analyze the relationship between COPD as measured by self-report and chronic symptoms (chronic cough and chronic phlegm) and cognitive impairment and to investigate if there are any effect modifications for a number of variables including sex, urbanicity, geographic region, educational level, smoking status, alcohol drinking, and indoor air pollution.

\section{Methods}

\section{Study population}

The study population was from China Chronic Disease and Risk Factor Surveillance (CCDRFS) conducted in 2010-2011. CCDRFS is a cross-sectional survey of Chinese adults aged 18 years and above aiming to investigate the prevalence of main chronic diseases and related risk factors in People's Republic of China. The subjects were selected from nationally representative disease surveillance points (DSP) system covering all 31 provinces, autonomous regions, and municipalities in People's Republic of China. Detailed descriptions of the survey were published elsewhere. ${ }^{10,11}$ Briefly, a multistage stratified random sampling was used to select participants from all 161 DSPs. In the first stage, four subdistricts in urban areas or townships in rural areas were selected from each site with probability proportional to size. In the second stage, three neighborhood communities or administrative villages were selected with probability proportional to size. In the third stage, households within each neighborhood community or administrative village were listed, and 50 households were randomly selected. In the final stage, one person who was at least 18 years old was selected randomly from each household using a Kish selection table. ${ }^{11}$ The overall response rate was $90.5 \%$. All recruited residents were invited to participate in the survey at a convenient and accessible site or at home. A standardized questionnaire was administered by trained interviewers during a face-toface interview. Data collected in the questionnaire included demographics, chronic disease-related lifestyle factors, and personal and family medical history. The study received ethics approval from the Ethics Committee of the Chinese Center for Disease Control and Prevention. All participants gave written informed consent for the study.

\section{Cognitive assessment}

For participants aged over 60 , the following three questions were asked about their memory status: 1) Is your memory getting worse compared to 12 months ago? 2) Do you think your memory is worse than that of your relatives, colleagues, or neighbors of your same age? 3) Do your family members, relatives, or neighbors think you have a bad memory? Subjects with an affirmative answer to any of the three questions were given a Mini-Mental State Examination (MMSE). MMSE is the best-known and the most often used short screening tool for providing an overall measure of cognitive impairment in clinical, research, and community settings. ${ }^{12}$ Of nearly 100,000 participants in the CCDRFS, 16,629 elderly subjects aged over 60 with complete data were included in the analysis in this report.

We used education-specific cut-off value to define cognitive impairment according to recommended guidelines in People's Republic of China; out of the total 30 points in MMSE, an individual was defined as cognitive impairment if score $\leq 17$ for illiterate group, score $\leq 20$ for primary school group, and score $\leq 24$ for middle school and above group. ${ }^{13}$

\section{Assessment of COPD and other variables}

Although spirometry is required for clinical diagnosis of COPD and there has been greater emphasis on airflow limitation in COPD, the most recent Global Initiative for Chronic Obstructive Lung Disease executive summary ${ }^{14}$ highlights that COPD patients should always include assessment of respiratory symptoms. It is clear that chronic respiratory symptoms remain useful and important not only in clinical practice but also for epidemiological purposes. We therefore assessed COPD by the following concepts: 1) Self-reported COPD: Subjects who answered the following question 
affirmatively were classified as having self-reported COPD: "Do you have chronic bronchitis or emphysema or COPD diagnosed by a health professional?" 2) Chronic cough or chronic phlegm: the Medical Research Council respiratory questionnaire was used to assess respiratory symptoms and subjects who usually had cough or phlegm first thing in the morning or either during the day or at night for at least 3 months were defined as having chronic cough or chronic phlegm.

All DSPs from 31 provinces were classified into eastern (8), central (11), and western (12) depending on geographic distribution according to China National Bureau of Statistics. Each geographic group included urban DSPs and rural DSPs and urbanicity for the subjects was defined according to their residence (either in urban or in rural). The distributions of all urban and rural DSPs are shown in Figure 1. Smoking status was classified as never smokers and ever smokers. Educational level was classified as illiterate, primary school, and middle school and above according to their highest education. Exposure to indoor air pollution was defined if participants reported use of coal, charcoal, crop residues, wood, or animal dung as the main source of cooking fuel. Alcohol drinking was defined if participants reported drinking any alcoholic beverages in the past 12 months.

\section{Statistical analysis}

Participants aged 60 years and above were included in the analysis. Estimates of prevalence of cognitive impairment were calculated separately in men and women overall and for subgroups stratified by age, education, marital status, region, urban/rural, and chronic respiratory conditions. All calculations were weighted to represent the overall national population. Weight coefficients were derived from 2010 China Census and the sampling scheme of the survey, incorporating the sampling weight, nonresponse weight, and poststratification weight. ${ }^{15}$ Logistic regression (survey logistic procedure for stratified cluster sampling) was applied to examine the relationship between COPD (self-reported COPD, chronic cough, and chronic phlegm) and cognitive impairment, from which odds ratio (OR) and 95\% confidence interval $(95 \% \mathrm{CI})$ were computed. The model was adjusted by forcing potential confounders (age, sex, geographic region, urban/rural, marital status, education, smoking status, alcohol drinking, and indoor air pollution) into the model. Interaction terms of variables (sex, urbanicity, region, education, smoking status, alcohol drinking, and indoor air pollution) and COPD were fitted in the model to test for any effect modifications. Statistical analyses were performed with SAS system, version 9.3 (SAS Institute Inc., Cary, NC, USA).

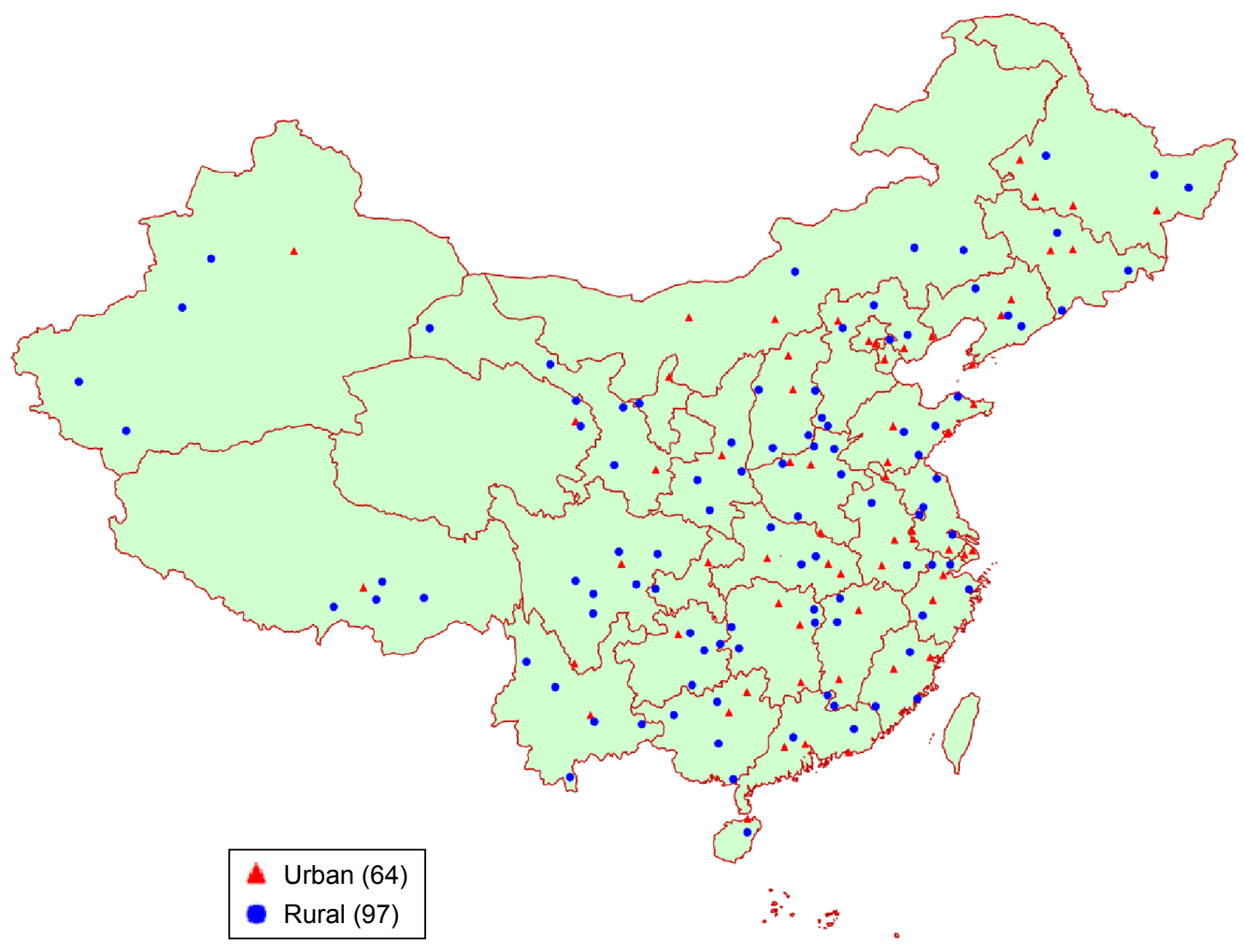

Figure I Geographic distribution of I6I DSPs in People's Republic of China. Abbreviation: DSP, disease surveillance point. 


\section{Results}

\section{Study subjects}

Of 16,629 subjects aged 60 years and above with complete data, there were 7,905 men $(48.7 \%)$ and 8,724 women $(51.3 \%), 7,072$ in urban areas $(32.6 \%)$ and 9,557 in rural areas $(67.4 \%)$. Subjects from eastern, central, and western region were $41.4 \%, 30.9 \%$, and $27.7 \%$, respectively. Characteristics of the study population are shown in Table 1. A greater proportion of subjects were illiterate in women than in men $(48.9 \%$ vs $19.7 \%$ ). A total of $62.8 \%$ of men smoked while only $6.5 \%$ women were smokers. Subjects with chronic cough, chronic phlegm, and COPD were $7.0 \%, 6.8 \%$, and $6.3 \%$, respectively, with men higher than women for all conditions.

\section{Prevalence of cognitive impairment}

A total of 5,672 subjects were assessed by MMSE. The prevalence of cognitive impairment among people aged 60 years and older was $9.4 \%(95 \%$ CI $7.7,11.1)$. As shown

Table I Characteristics of study participants

\begin{tabular}{|c|c|c|c|}
\hline & Total (\%) & Men (\%) & Women (\%) \\
\hline Total & $16,629(100.0)$ & 7,905 (48.7) & $8,724(5 \mid .3)$ \\
\hline \multicolumn{4}{|l|}{ Urbanicity } \\
\hline Urban & $7,072(32.6)$ & $3,219(32.2)$ & $3,853(32.9)$ \\
\hline Rural & $9,557(67.4)$ & $4,686(67.8)$ & $4,87 \mathrm{I}(67.1)$ \\
\hline \multicolumn{4}{|l|}{ Age group (years) } \\
\hline $60-69$ & $|0,97|(58.4)$ & $5,205(60.6)$ & $5,766(56.3)$ \\
\hline $70-79$ & $4,824(32.6)$ & $2,330(31.9)$ & $2,494(33.3)$ \\
\hline $80+$ & $834(9.0)$ & $370(7.5)$ & $464(10.4)$ \\
\hline \multicolumn{4}{|l|}{ Region } \\
\hline East & $6,540(4 I .4)$ & $3,156(4 \mid .0)$ & 3,384 (4I.8) \\
\hline Central & $4,944(30.9)$ & $2,318(31.1)$ & $2,626(30.8)$ \\
\hline West & $5,145(27.7)$ & $2,431(27.9)$ & $2,714(27.4)$ \\
\hline \multicolumn{4}{|l|}{ Marital status } \\
\hline Single & $158(1.0)$ & I $14(1.7)$ & $44(0.4)$ \\
\hline Married & $12,389(73.0)$ & $6,518(81.4)$ & $5,871(64.9)$ \\
\hline Divorced or widowed & $4,082(26.0)$ & $1,273(16.9)$ & $2,809(34.6)$ \\
\hline \multicolumn{4}{|l|}{ Educational level } \\
\hline Illiterate & $5,027(34.7)$ & I,405 (19.7) & $3,622(48.9)$ \\
\hline Primary school & $6,823(40.6)$ & $3,575(46.7)$ & $3,248(34.8)$ \\
\hline Middle school & $4,779(24.7)$ & $2,925(33.6)$ & $\mathrm{I}, 854(16.3)$ \\
\hline \multicolumn{4}{|l|}{ Smoking status } \\
\hline Never smoked & II,073 (66.0) & $2,934(37.2)$ & $8,139(93.5)$ \\
\hline Smoker & $5,556(34.0)$ & $4,971(62.8)$ & $585(6.5)$ \\
\hline \multicolumn{4}{|l|}{ Alcohol drinking } \\
\hline No & I0,59| (7I.2) & $3,780(53.3)$ & $6,811(88.9)$ \\
\hline Yes & $4,403(28.8)$ & $3,506(46.7)$ & $897(I I . I)$ \\
\hline \multicolumn{4}{|l|}{ Indoor air pollution } \\
\hline No & $8,374(46.1)$ & $3,819(45.3)$ & $4,555(46.8)$ \\
\hline Yes & $8,255(53.9)$ & $4,086(54.7)$ & $4,169(53.2)$ \\
\hline \multicolumn{4}{|l|}{ Conditions } \\
\hline Chronic cough & I, I54 (7.0) & $705(9.0)$ & $449(5.1)$ \\
\hline Chronic phlegm & $1,092(6.8)$ & $697(9.2)$ & $395(4.6)$ \\
\hline Self-reported COPD & I,08I (6.3) & $623(7.8)$ & $458(4.9)$ \\
\hline
\end{tabular}

Abbreviation: COPD, chronic obstructive pulmonary disease. in Table 2, the prevalence rate was higher in rural than in urban areas and increased with age. Subjects with higher education had a lower prevalence of cognitive impairment in both men and women. Subjects with exposure to indoor air pollution had twofold prevalence rates compared with the no exposure group for both men and women. Subjects reporting chronic respiratory conditions had a consistently higher prevalence of cognitive impairment compared with those without respiratory conditions.

\section{COPD and cognitive impairment}

As shown in Table 3, chronic phlegm was associated with significantly higher prevalence of cognitive impairment in both crude and adjusted models (adjusted OR 1.46, 95\% CI 1.11, 1.93). After adjusting for age, sex, marital status, smoking status, geographic region, urban/rural, education, alcohol drinking, and indoor air pollution, chronic cough and self-reported COPD were not associated with cognitive impairment.

In stratified analysis, there was a significant association between chronic cough and phlegm and prevalence of cognitive impairment in men but not in women. All three indicators for COPD were strongly associated with cognitive impairment in urban areas (Table 4). Chronic phlegm was also associated with increased cognitive impairment in rural areas. There were no significant effect modifications for sex, regions, educational level, smoking status, and alcohol drinking. Indoor air pollution can modify the effects on cognitive impairment for chronic cough $(P$ for interaction $=0.01)$ and chronic phlegm $(P$ for interaction $=0.02)$.

\section{Discussion}

To our knowledge, this is the first study conducted in People's Republic of China to investigate the relationship between COPD and cognitive impairment among Chinese elderly population based on a large nationally representative sample covering all 31 provinces, municipalities, and autonomous regions. We found strong associations between self-reported COPD, chronic cough, chronic phlegm, and cognitive impairment in elderly people aged 60 years and above in urban areas. Effect modifications were found for indoor air pollution on the association between chronic respiratory symptoms and cognitive impairment.

The prevalence of self-reported COPD in the current study was in keeping with previous estimates of the same age group. ${ }^{16}$ The prevalence of cognitive impairment estimated in our study, however, was lower than the reports of previous studies carried out in a number of cities or regions in People's Republic of China. ${ }^{17,18}$ Another study assessed the cognitive 
Table 2 Prevalence of cognitive impairment in Chinese elderly aged 60 years and above

\begin{tabular}{|c|c|c|c|c|c|c|}
\hline & \multicolumn{2}{|c|}{ Men } & \multicolumn{2}{|c|}{ Women } & \multicolumn{2}{|l|}{ Total } \\
\hline & $\mathbf{n}$ & Prevalence $(95 \% \mathrm{Cl})$ & $\mathbf{n}$ & Prevalence $(95 \% \mathrm{CI})$ & $\mathbf{n}$ & Prevalence $(95 \% \mathrm{Cl})$ \\
\hline Total & $44 I$ & $7.1(5.3,8.9)$ & 738 & II.7 (9.4, I3.9) & $\mathrm{I}, \mathrm{I} 79$ & $9.4(7.7,11.1)$ \\
\hline \multicolumn{7}{|l|}{ Urbanicity } \\
\hline Urban & 112 & $3.6(2.8,4.5)$ & 190 & $6.7(4.5,8.9)$ & 302 & $5.2(4.0,6.4)$ \\
\hline Rural & 329 & $8.7(6.2,11.2)$ & 548 & I4.I (II.0, I7.2) & 877 & II.5 (9.1, I3.8) \\
\hline \multicolumn{7}{|l|}{ Age group (years) } \\
\hline $60-69$ & 195 & $4.6(2.9,6.4)$ & 313 & $6.5(5.0,8.0)$ & 508 & $5.6(4.2,6.9)$ \\
\hline 70-79 & 200 & $10.0(7.7,12.3)$ & 326 & $15.5(\mid 2.5,18.5)$ & 526 & $12.9(10.5,15.3)$ \\
\hline $80+$ & 46 & $14.1(9.5,18.8)$ & 99 & $27.2(20.0,34.3)$ & 145 & $21.9(17.5,26.3)$ \\
\hline \multicolumn{7}{|l|}{ Region } \\
\hline East & 129 & $5.0(3.5,6.6)$ & 258 & $9.9(7.1,12.6)$ & 387 & $7.5(5.8,9.3)$ \\
\hline Central & 144 & $9.7(4.7,14.7)$ & 209 & I5.2 $(9.8,20.6)$ & 353 & I2.5 (8.I, I6.9) \\
\hline West & 168 & $7.1(5.5,8.6)$ & 271 & $10.4(7.8,13.1)$ & 439 & $8.8(7.1,10.5)$ \\
\hline \multicolumn{7}{|l|}{ Marital status } \\
\hline Single & 13 & $10.1(4.0,16.2)$ & 6 & $8.8(0.5,18.1)$ & 19 & $9.9(4.4,15.3)$ \\
\hline Married & 330 & $6.5(4.5,8.5)$ & 413 & $9.4(7.3,11.5)$ & 743 & $7.8(6.1,9.6)$ \\
\hline Divorced or widowed & 98 & $9.4(7.2,11.6)$ & 319 & $16.0(12.9,19.1)$ & 417 & $13.9(11.5,16.3)$ \\
\hline \multicolumn{7}{|l|}{ Educational level } \\
\hline Illiterate & 126 & II.3 (8.6, I3.9) & 469 & $16.9(13.8,20.0)$ & 595 & $15.3(12.8,17.9)$ \\
\hline Primary school & 196 & $7.1(5.2,9.0)$ & 193 & $7.2(5.3,9.0)$ & 389 & $7.2(5.5,8.8)$ \\
\hline Middle school & 119 & $4.5(2.4,6.5)$ & 76 & $5.6(3.4,7.8)$ & 195 & $4.8(3.1,6.6)$ \\
\hline \multicolumn{7}{|l|}{ Smoking status } \\
\hline Never smoked & 195 & $8.6(5.5,11.7)$ & 669 & II.3 (9.2, I3.5) & 864 & $10.6(8.6,12.6)$ \\
\hline Smoker & 246 & $6.2(4.9,7.4)$ & 69 & $16.4(|I .5,2| .4)$ & 315 & $7.2(5.7,8.6)$ \\
\hline \multicolumn{7}{|l|}{ Alcohol drinking } \\
\hline No & 238 & $7.8(5.8,9.9)$ & 601 & I2.3 $(9.8,14.8)$ & 839 & $10.6(8.6,12.7)$ \\
\hline Yes & 158 & $6.0(4.2,7.7)$ & 50 & $6.5(4.3,8.6)$ & 208 & $6.1(4.4,7.7)$ \\
\hline \multicolumn{7}{|l|}{ Indoor air pollution } \\
\hline No & 143 & $4.8(3.2,6.5)$ & 234 & $6.6(5.2,8.1)$ & 377 & $5.8(4.4,7.1)$ \\
\hline Yes & 298 & $8.9(6.0,11.8)$ & 504 & $16.1(12.7,19.6)$ & 802 & $12.6(9.9,15.2)$ \\
\hline \multicolumn{7}{|l|}{ Chronic cough } \\
\hline No & 386 & $6.8(5.0,8.6)$ & 674 & I I. $5(9.2,13.8)$ & $\mathrm{I}, 060$ & $9.3(7.5,11.0)$ \\
\hline Yes & 55 & $9.6(5.9,13.2)$ & 64 & $14.6(10.3,18.9)$ & 119 & II.5 (8.4, I4.6) \\
\hline \multicolumn{7}{|l|}{ Chronic phlegm } \\
\hline No & 384 & $6.8(4.9,8.6)$ & 683 & II.4 (9.2, I3.7) & 1,067 & $9.2(7.5,10.9)$ \\
\hline Yes & 57 & $9.9(6.8,13.1)$ & 55 & $16.7(10.4,23.0)$ & 112 & I2.3 (8.7, I5.8) \\
\hline \multicolumn{7}{|l|}{ Self-reported COPD } \\
\hline No & 400 & $6.9(5.0,8.9)$ & 681 & II.6 (9.3, I3.9) & $|, 08|$ & $9.4(7.6,11.1)$ \\
\hline Yes & 41 & $8.5(4.5,12.5)$ & 57 & $13.2(9.0,17.5)$ & 98 & $10.4(7.4,13.9)$ \\
\hline
\end{tabular}

Abbreviations: $\mathrm{Cl}$, confidence interval; COPD, chronic obstructive pulmonary disease.

function in Chinese subjects in Singapore and found that the prevalence of cognitive impairment was $15.2 \%$ among people aged over 60 years, which is in the same range as reported in Caucasian and other Asian populations. ${ }^{19}$ The relatively lower estimates in the current study might be due to the relatively healthier national sample and the measurement of cognitive impairment was only based on MMSE.

The observed association between COPD and cognitive impairment in our study was also reported in cohort studies and case-control studies conducted in developed countries. ${ }^{5,6,20}$ A most recent review indicated that the majority of studies support at least some independent association between lung function and cognitive performance. ${ }^{21}$
A comprehensive longitudinal study of over 10,000 healthy men and women with repeated cognitive assessments between 1990 and 2006 showed that impaired lung function was independently associated with worse cognitive function at baseline and higher subsequent risk of dementia hospitalization. ${ }^{6}$ However, previous studies showed mixed results, ${ }^{7,8,22}$ mainly due to methodological issues such as diagnostic uncertainty, cross-sectional design, small sample size, or lack of appropriate referent group.

Previous studies indicated that the association of lung function with cognitive impairment was stronger in women than in men, ${ }^{6,23}$ and similar results have been reported for smoking. ${ }^{24}$ However, we did not find any associations for 
Table 3 Crude and adjusted ORs and $95 \% \mathrm{Cl}$ for the effects of COPD, chronic respiratory symptoms and other covariates on cognitive impairment

\begin{tabular}{|c|c|c|}
\hline & $\begin{array}{l}\text { Crude OR } \\
(95 \% \mathrm{Cl})\end{array}$ & $\begin{array}{l}\text { Adjusted OR } \\
(95 \% \mathrm{Cl})\end{array}$ \\
\hline \multicolumn{3}{|l|}{ Sex } \\
\hline Men & I & 1 \\
\hline Women & $\mathrm{I} .74(\mathrm{I} .3 \mathrm{I}, 2.3 \mathrm{I})^{*}$ & $1.33(0.95,1.86)$ \\
\hline \multicolumn{3}{|l|}{ Age group } \\
\hline $60-69$ & 1 & I \\
\hline $70-79$ & $2.5 \mathrm{I}(2.10,3.00)^{*}$ & $2.17(1.82,2.59)^{*}$ \\
\hline $80+$ & $4.74(3.64,6.18)^{*}$ & $3.30(2.47,4.4 \mathrm{I})^{*}$ \\
\hline \multicolumn{3}{|l|}{ Marital status } \\
\hline Single & 1 & I \\
\hline Married & $0.78(0.39,1.55)$ & $0.67(0.30, I .5 \mathrm{I})$ \\
\hline Divorced or widowed & I.48 $(0.76,2.86)$ & $0.84(0.38,1.87)$ \\
\hline \multicolumn{3}{|l|}{ Educational level } \\
\hline Illiterate & 1 & I \\
\hline Primary school & $0.43(0.34,0.53)^{*}$ & $0.68(0.52,0.88)^{*}$ \\
\hline Middle school & $0.28(0.19,0.42)^{*}$ & $0.67(0.44,1.00)$ \\
\hline \multicolumn{3}{|l|}{ Urbanicity } \\
\hline Urban & 1 & I \\
\hline Rural & $2.35(1.66,3.30)^{*}$ & $1.64(1.16,2.3 \mathrm{I})^{*}$ \\
\hline \multicolumn{3}{|l|}{ Region } \\
\hline East & 1 & I \\
\hline Central & $1.76(1.09,2.83)^{*}$ & I. $47(0.92,2.34)$ \\
\hline West & $1.18(0.85,1.64)$ & I.02 $(0.74,1.39)$ \\
\hline \multicolumn{3}{|l|}{ Smoking status } \\
\hline Never smoked & 1 & I \\
\hline Smoker & $0.65(0.55,0.78)^{*}$ & $0.94(0.67, \mathrm{I} .34)$ \\
\hline \multicolumn{3}{|l|}{ Alcohol drinking } \\
\hline No & 1 & I \\
\hline Yes & $0.54(0.42,0.70)^{*}$ & $0.74(0.57,0.97)^{*}$ \\
\hline \multicolumn{3}{|l|}{ Indoor air pollution } \\
\hline No & 1 & I \\
\hline Yes & $2.35(1.68,3.28)^{*}$ & $1.72(1.19,2.49)^{*}$ \\
\hline \multicolumn{3}{|l|}{ Chronic cough } \\
\hline No & 1 & I \\
\hline Yes & I.27 (0.9।, I.75) & I.3। $(0.95,1.80)$ \\
\hline \multicolumn{3}{|l|}{ Chronic phlegm } \\
\hline No & 1 & I \\
\hline Yes & $1.38(1.01,1.87)^{*}$ & $1.46(1.11,1.93)^{*}$ \\
\hline \multicolumn{3}{|l|}{ Self-reported COPD } \\
\hline No & I & 1 \\
\hline Yes & $1.12(0.80,1.56)$ & I.2I $(0.83,1.77)$ \\
\hline
\end{tabular}

Note: ${ }^{*} P<0.05$.

Abbreviations: $\mathrm{Cl}$, confidence interval; COPD, chronic obstructive pulmonary disease; OR, odds ratio.

never smokers and women and there were no interactions between COPD with educational level, region, and alcohol drinking. Differences in the study population and definitions for cognitive outcome measurement could be responsible for the inconsistency. The strong associations observed for men, smokers, people living in urban areas, and without indoor air pollution implied that chronic respiratory symptoms might be an important factor for cognitive impairment among this group of people. Early intervention should be targeted to urban Chinese elderly smokers to prevent cognitive function decline.

Several possible mechanisms could explain the association of COPD with cognitive impairment. Previous studies showed that smoking is associated with prospective memory deficits ${ }^{25}$ and the increased risk of cognitive decline in individuals with COPD may be as a result of smoking behavior, which occurs more frequently in those with chronic respiratory conditions. A mechanism proposed for the cognitive impairment in COPD patients is the neuronal damage mediated by chronic hypoxia as a direct result of respiratory limitations. ${ }^{22,26}$ Furthermore, recent studies suggest that COPD is associated with reduced hippocampal and gray matter volumes, which appear to correlate with measures of cognitive function..$^{27,28}$ There are also hypotheses that diabetes and cardiovascular disease associated with chronic respiratory diseases might cause cognitive impairment. ${ }^{29-32}$

The study population included in the analysis represents the largest study addressing the relation between COPD and cognitive impairment in People's Republic of China. Subjects were randomly selected from all 31 provinces, autonomous regions, and municipalities in People's Republic of China and the large sample size allowed us to examine the association in subgroups. The study population came from a large survey with measurements of many risk factors for chronic diseases; therefore, we can adjust for many potential confounders in the analysis. Although the prevalence of cognitive impairment in Chinese population estimated in this study is not as high as those reported in developed countries, the large absolute number of people with cognitive impairment will bring huge burden to the Chinese society. Learning from developed countries where experiences have been gained might provide insights into reducing the burden caused by cognitive impairment in People's Republic of China.

One limitation of the study is its cross-sectional nature. We cannot infer temporal association between COPD and cognitive impairment. Although we asked the subjects whether they had respiratory symptoms in the past 12 months and measured the cognitive function on the day of interview, it is difficult to conclude that chronic cough, chronic phlegm, or COPD are the risk factors for cognitive impairment, as the cognitive disorder may lead to disability and easily comorbid with other chronic diseases including respiratory diseases. Second, we were not able to adjust for some potential risk factors for cognitive impairment such as body mass index and physical activity ${ }^{22}$ and we are concerned that our models may not have entirely eliminated potential residual confounding. Previous studies have shown inconsistent 
Table 4 Adjusted ORs for the effects of COPD, chronic respiratory symptoms on cognitive impairment in stratified analysis*

\begin{tabular}{|c|c|c|c|c|c|c|}
\hline & $\begin{array}{l}\text { Chronic cough } \\
\text { OR }(95 \% \mathrm{Cl})\end{array}$ & $P$ for interaction & $\begin{array}{l}\text { Chronic phlegm } \\
\text { OR }(95 \% \mathrm{Cl})\end{array}$ & $P$ for interaction & $\begin{array}{l}\text { Self-reported COPD } \\
\text { OR }(95 \% \mathrm{Cl})\end{array}$ & $P$ for interaction \\
\hline Sex & & 0.45 & & 0.95 & & 0.80 \\
\hline Men & $1.45(1.00,2.11)^{*}$ & & $1.53(1.08,2.17)^{*}$ & & $1.30(0.75,2.25)$ & \\
\hline Women & $1.12(0.74,1.70)$ & & $1.37(0.89,2.09)$ & & I.12 (0.7I, I.77) & \\
\hline Urban & & 0.09 & & 0.53 & & 0.08 \\
\hline Urban & $1.80(1.24,2.62)^{*}$ & & I.74 (I.08, 2.79)* & & $1.72(1.18,2.50)^{*}$ & \\
\hline Rural & I. $17(0.79,1.75)$ & & $1.42(1.03,1.96)^{*}$ & & $1.04(0.65,1.66)$ & \\
\hline Region & & 0.29 & & 0.27 & & 0.63 \\
\hline East & $1.81(1.02,3.10)^{*}$ & & $1.80(1.27,2.57)^{*}$ & & I.42 $(0.78,2.59)$ & \\
\hline Central & $0.96(0.59,1.56)$ & & I.46 (0.9I, 2.35) & & I.08 $(0.52,2.26)$ & \\
\hline West & I.27 $(0.77,2.08)$ & & $1.24(0.70,2.19)$ & & $1.15(0.66,2.03)$ & \\
\hline Educational level & & 0.24 & & 0.98 & & 0.54 \\
\hline Illiterate & $1.05(0.69,1.60)$ & & I.42 $(0.90,2.23)$ & & $1.17(0.71,1.94)$ & \\
\hline Primary school & $1.67(1.08,2.57)^{*}$ & & $1.61(1.02,2.52)^{*}$ & & I.45 $(0.93,2.27)$ & \\
\hline Middle school & I.3I $(0.74,2.32)$ & & $1.24(0.69,2.24)$ & & $0.67(0.31,1.46)$ & \\
\hline Smoking status & & 0.29 & & 0.88 & & 0.84 \\
\hline Never smoked & I.II $(0.69$, I.78) & & I.4I $(0.97,2.04)$ & & I.I5 (0.7I, I.87) & \\
\hline Smoker & $1.5 \mathrm{I}(1.06,2.14)^{*}$ & & $1.48(1.01,2.18)^{*}$ & & I.24 $(0.70,2.20)$ & \\
\hline Alcohol drinking & & 0.98 & & 0.93 & & 0.97 \\
\hline No & $1.28(0.90,1.83)$ & & $1.47(1.06,2.03)^{*}$ & & I. $19(0.79,1.79)$ & \\
\hline Yes & $1.26(0.72,2.20)$ & & $1.38(0.76,2.49)$ & & $1.22(0.57,2.59)$ & \\
\hline Indoor air pollution & & 0.01 & & 0.02 & & 0.11 \\
\hline No & I.84 (I.22, 2.77)* & & $2.21(1.50,3.24)^{*}$ & & I.52 $(0.97,2.39)$ & \\
\hline Yes & $1.05(0.74,1.49)$ & & I.I5 (0.78, I.70) & & $1.03(0.67,1.57)$ & \\
\hline
\end{tabular}

Notes: ORs were adjusted for age, sex, marital status, educational level, urban/rural, region, smoking status, alcohol drinking, and indoor air pollution. $* P<0.05$. Abbreviations: COPD, chronic obstructive pulmonary disease; OR, odds ratio; $\mathrm{Cl}$, confidence interval.

results with regard to the association between body mass index and physical activity and cognitive function. ${ }^{33,34}$ It was therefore unlikely that adding these two factors into the model would have yielded significantly different results. Chronic diseases, such as diabetes and cardiovascular diseases and traumatic brain injury and developmental disabilities, are potentially related to cognitive impairment but not included in our model. ${ }^{2,29,30}$ Mental disorder is also a very important factor causing cognitive impairment but not assessed in the current survey. Future studies should consider these conditions and include mental disorders in the selection of study participants. Third, the outcome measurement was based on MMSE, as a screening tool, and we were not able to ascertain the clinical diagnosis of mild cognitive impairment or dementia. However, illustrating an association between COPD and early stages of cognitive impairment could also have important implications to the aging society. Fourth, the MMSE was only administered to participants who know their potential memory problems. The exclusion of people unaware of their memory problems may underestimate the prevalence of cognitive impairment. Furthermore, our measurements for COPD only included self-report without the objective spirometry test to confirm diagnosis of COPD and assess severity of the disease. Those with cognitive impairment may be less likely to self-report history of COPD; however, this makes our estimate conservative and strengthens our conclusions. Although self-reporting of health conditions is an accepted methodology for large, nationally representative population-based surveys, lung function should be measured to determine the COPD status and its severity to explore the impact on cognitive function more accurately in future studies.

The strong associations between COPD and cognitive impairment have important public health and clinical implications. The doctors (mainly respiratory physicians) and other related health professionals providing medical service for COPD patients should be aware of their increased risk for cognitive decline. Smoking prevention and cessation should be encouraged to reduce systematic inflammation associated with high risk of cognition decline. Physical activity should also be promoted as related to hypoxia-induced high risks for cognitive impairment.

In conclusion, there was strong association between COPD and cognitive impairment in urban Chinese elderly population. Our study enhances the current understanding of the relationship between chronic respiratory disease and cognitive decline in fast aging developing countries.

\section{Author contributions}

All authors contributed toward data analysis, drafting and revising the paper and agree to be accountable for all aspects of the work. 


\section{Disclosure}

The authors report no conflicts of interest in this work.

\section{References}

1. Zhong N, Wang C, Yao W, et al. Prevalence of chronic obstructive pulmonary disease in China: a large, population-based survey. Am J Respir Crit Care Med. 2007;176:753-760.

2. Winblad B, Palmer K, Kivipelto M, et al. Mild cognitive impairment beyond controversies, towards a consensus: report of the International Working Group on Mild Cognitive Impairment. J Intern Med. 2004;256: 240-246.

3. Villeneuve S, Pepin V, Rahayel S, et al. Mild cognitive impairment in moderate to severe COPD: a preliminary study. Chest. 2012;142: $1516-1523$.

4. Rusanen M, Ngandu T, Laatikainen T, et al. Chronic obstructive pulmonary disease and asthma and the risk of mild cognitive impairment and dementia: a population based CAIDE study. Curr Alzheimer Res. 2013;10:549-555.

5. Chyou PH, White LR, Yano K, et al. Pulmonary function measures as predictors and correlates of cognitive functioning in later life. $\mathrm{Am}$ J Epidemiol. 1996;143:750-756.

6. Pathan SS, Gottesman RF, Mosley TH, Knopman DS, Sharrett AR, Alonso A. Association of lung function with cognitive decline and dementia: the Atherosclerosis Risk in Communities (ARIC) Study. Eur J Neurol. 2011;18:888-898.

7. Kozora E, Filley CM, Julian LJ, et al. Cognitive functioning in patients with chronic obstructive pulmonary disease and mild hypoxemia compared with patients with mild Alzheimer disease and normal controls. Neuropsychiatry Neuropsychol Behav Neurol. 1999;12:178-183.

8. Isoaho R, Puolijoki H, Huhti E, Laippala P, Kivela SL. Chronic obstructive pulmonary disease and cognitive impairment in the elderly. Int Psychogeriatr. 1996;8:113-125.

9. Zeng Y, Linda KG. Population aging and old-age care in China. In: Dannefer Dale PC, editor. Sage Handbook of Social Gerontology: Thousand Oaks, CA: Sage Publications; 2010:420-429.

10. Li Y, Wang L, Jiang Y, Zhang M, Wang L. Risk factors for noncommunicable chronic diseases in women in China: surveillance efforts. Bull World Health Organ. 2013;91:650-660.

11. Xu Y, Wang $\mathrm{L}, \mathrm{He} \mathrm{J}$, et al. Prevalence and control of diabetes in Chinese adults. JAMA. 2013;310:948-959.

12. Nieuwenhuis-Mark RE. The death knoll for the MMSE: has it outlived its purpose? J Geriatr Psychiatry Neurol. 2010;23:151-157.

13. Zhang MY, Katzman R, Salmon D, et al. The prevalence of dementia and Alzheimer's disease in Shanghai, China: impact of age, gender, and education. Ann Neurol. 1990;27:428-437.

14. Vestbo J, Hurd SS, Agusti AG, et al. Global strategy for the diagnosis, management, and prevention of chronic obstructive pulmonary disease: GOLD executive summary. Am J Respir Crit Care Med. 2013;187: 347-365.

15. Hu N, Jiang Y, Li Y, et al. Weighting method for 2010 China chronic disease and risk factor surveillance. China Health Stat. 2012;3:79-81.

16. Yin P, Zhang M, Li Y, Jiang Y, Zhao W. Prevalence of COPD and its association with socioeconomic status in China: findings from China Chronic Disease Risk Factor Surveillance 2007. BMC Public Health. 2011;11:586.

International Journal of COPD

\section{Publish your work in this journal}

The International Journal of COPD is an international, peer-reviewed journal of therapeutics and pharmacology focusing on concise rapid reporting of clinical studies and reviews in COPD. Special focus is given to the pathophysiological processes underlying the disease, intervention programs, patient focused education, and self management protocols.
17. Ding D, Zhao Q, Guo Q, et al. Prevalence of mild cognitive impairment in an urban community in China: a cross-sectional analysis of the Shanghai Aging Study. Alzheimers Dement. 2015;11:300-309.

18. Xu S, Xie B, Song M, et al. High prevalence of mild cognitive impairment in the elderly: a community-based study in four cities of the Hebei Province, China. Neuroepidemiology. 2014;42:123-130.

19. Hilal S, Ikram MK, Saini M, et al. Prevalence of cognitive impairment in Chinese: epidemiology of dementia in Singapore study. J Neurol Neurosurg Psychiatry. 2013;84:686-692.

20. Thakur N, Blanc PD, Julian LJ, et al. COPD and cognitive impairment: the role of hypoxemia and oxygen therapy. Int J Chron Obstruct Pulmon Dis. 2010;5:263-269.

21. Dodd JW. Lung disease as a determinant of cognitive decline and dementia. Alzheimers Res Ther. 2015;7:32.

22. Dodd JW, Getov SV, Jones PW. Cognitive function in COPD. Eur Respir J. 2010;35:913-922.

23. Alonso A, Mosley TH Jr, Gottesman RF, Catellier RF, Sharrett AR, Coresh J. Risk of dementia hospitalisation associated with cardiovascular risk factors in midlife and older age: the Atherosclerosis Risk in Communities (ARIC) study. J Neurol Neurosurg Psychiatry. 2009;80: 1194-1201.

24. Bretsky PM, Buckwalter JG, Seeman TE, et al. Evidence for an interaction between apolipoprotein E genotype, gender, and Alzheimer disease. Alzheimer Dis Assoc Disord. 1999;13:216-221.

25. Heffernan TM, Ling J, Parrott AC, et al. Self-rated everyday and prospective memory abilities of cigarette smokers and non-smokers: a web-based study. Drug Alcohol Depend. 2005;78:235-241.

26. Peers C, Dallas ML, Boycott HE, Scraqq JL, Pearson HA, Boyle JP. Hypoxia and neurodegeneration. Ann N Y Acad Sci. 2009;1177: 169-177.

27. Li J, Fei GH. The unique alterations of hippocampus and cognitive impairment in chronic obstructive pulmonary disease. Respir Res. $2013 ; 14: 140$

28. Zhang H, Wang X, Lin J, et al. Reduced regional gray matter volume in patients with chronic obstructive pulmonary disease: a voxel-based morphometry study. AJNR Am J Neuroradiol. 2013;34:334-339.

29. Alonso A, Jacobs DR Jr, Menotti A, et al. Cardiovascular risk factors and dementia mortality: 40 years of follow-up in the Seven Countries Study. J Neurol Sci. 2009;280:79-83.

30. Newman AB, Fitzpatrick AL, Lopez O, et al. Dementia and Alzheimer's disease incidence in relationship to cardiovascular disease in the Cardiovascular Health Study cohort. J Am Geriatr Soc. 2005;53: 1101-1107.

31. Schroeder EB, Welch VL, Couper D, et al. Lung function and incident coronary heart disease: the Atherosclerosis Risk in Communities Study. Am J Epidemiol. 2003;158:1171-1181.

32. Yeh HC, Punjabi NM, Wang NY, et al. Vital capacity as a predictor of incident type 2 diabetes: the Atherosclerosis Risk in Communities study. Diabetes Care. 2005;28:1472-1479.

33. Schlosser Covell GE, Hoffman-Snyder CR, Wellik KE, et al. Physical activity level and future risk of mild cognitive impairment or dementia: a critically appraised topic. Neurologist. 2015;19:89-91.

34. Besser LM, Gill DP, Monsell SE, et al. Body mass index, weight change, and clinical progression in mild cognitive impairment and Alzheimer disease. Alzheimer Dis Assoc Disord. 2014;28:36-43.

This journal is indexed on PubMed Central, MedLine and CAS. The manuscript management system is completely online and includes a very quick and fair peer-review system, which is all easy to use. Visit $\mathrm{http}: / / \mathrm{www}$.dovepress.com/testimonials.php to read real quotes from published authors. 